\title{
Does Retirement Affect Residency Model?
}

\author{
Huaxia Jin \\ College of Economics, Jinan University, Guangzhou, China \\ Email:13523567759@163.com
}

How to cite this paper: Jin, H.X. (2018) Does Retirement Affect Residency Model? Open Journal of Social Sciences, 6, 159-166. https://doi.org/10.4236/jss.2018.66015

Received: May 15, 2018

Accepted: June 17, 2018

Published: June 20, 2018

Copyright (C) 2018 by author and Scientific Research Publishing Inc. This work is licensed under the Creative Commons Attribution International License (CC BY 4.0).

http://creativecommons.org/licenses/by/4.0/ (c) (i) Open Access

\begin{abstract}
This paper explores the impact of retirement on individual's residency model based on the data from the China Health and Retirement Longitudinal Study (CHARLS) of 2013 and 2015. The results show that retirement significantly reduces the probability of individual's sharing co-residence with their children, and the male individuals are more affected. China has entered an aging society, the welfare of the elderly has received widespread attention, and children should pay more attention to the elderly so that they can live happily in their old age.
\end{abstract}

\section{Keywords}

Retirement, Co-Residence, CHARLS

\section{Introduction}

By 2000, people aged over 60 and 65 were $10 \%$ and $7 \%$ of the population in China respectively (China Statistical Yearbook, 2001), indicating that China had entered an aging society, and the proportion of the elderly had increased year by year. By the end of 2017, people aged over 60 had exceeded to 241 million, accounting for $17.3 \%$ of the total population, people aged over 65 had a population of more than 158 million, accounting for $11.4 \%$ of the total population, higher than the international "aging society" standard; both aging population and the elderly dependency ratio are increasing year by year (Table 1).

Since China had entered an aging society in 2000, the size and proportion of the elderly population have grown at a relatively rapid rate, and their residency model has received more and more attention. Based on the data of the China Health and Retirement Longitudinal Study (CHARLS), this paper analyzes the impact of retirement on the individual's residency model of the elderly, what's more, the impact from the perspective of overall and different genders will be conducted, and it explores ways to improve their lives and welfare of the elderly. 
Table 1. Aging population and the elderly dependency ratio.

\begin{tabular}{cccc}
\hline Year & Aged over 60 (\%) & Aged over 65 (\%) & The elderly dependency ratio (\%) \\
\hline 2000 & 10.2 & 7.0 & 9.9 \\
2010 & 13.3 & 8.9 & 11.9 \\
2011 & 13.7 & 9.1 & 12.3 \\
2012 & 14.3 & 9.4 & 12.7 \\
2013 & 14.9 & 9.7 & 13.1 \\
2014 & 15.5 & 10.1 & 13.7 \\
2015 & 16.1 & 10.5 & 14.3 \\
2016 & 16.7 & 10.8 & 15 \\
2017 & 17.3 & 11.4 & - \\
\hline
\end{tabular}

Source of data: China Statistical Yearbook 2017.

For ease of analysis, this paper defines retirement as an activity which requires a retirement procedure. Based on the data from CHARLS of 2013 and 2015, individuals aged 45 to 75 who have retired or may retire later are selected as the study subjects; this paper investigates the influence of retirement on residency model of the elderly.

\section{Literature Review}

There are many factors that influence the residency model of the elderly. The probability of individual's sharing co-residence with their children will increase with the increasing of individual's age based on the Japanese micro-survey data in 1986 [1]. The individuals aged between 65 with 75 are more likely to sharing co-residence with their children than the individuals aged over 75 years old [2]. There are gender differences in the probability of individual's sharing co-residence with their children. The male individuals are more likely to sharing co-residence with their children than the female individuals [2] [3]. Marital status has a great impact on individual's residency model. Individuals are more likely to sharing co-residence with their children when they do not have a spouse [4]. The higher the level of education is, the lower the probability of sharing co-residence with their children is and the level of education is considered as a symbol of the individual's social status [5]. However, it is found that the educational background has little effect on the probability of individual's sharing co-residence with their children [1]. The elderly with good economic Condition are less likely to share co-residence with their children, and the individuals who have the ownership of their houses are more likely to live apart from their children [6]. The better the self-rated health status of the elderly is, the less likely they are to share co-residence with their children [5]. The poorer the self-care ability of the elderly is, the more likely they are to share co-residence with their children [7]. Children are generally considered to be able to take good care of their parents' lives, the bigger the number of children is, the more likely they are to 
share co-residence with their children [8]. The elderly without children are more likely to live alone [9].

There are three main aspects of research on retirement. The first is the influence of retirement on consumption. It is confirmed that retirement led to a decline in food consumption of urban residents in China [10]. The second is the effect of retirement on the well-being of the elderly. Retirement has significantly increased the sense of happiness of the residents based on the CHARLS survey data [11]. The third is the impact of retirement on health. Retirement at the normal retirement age has a significant negative impact on health condition among the male individuals based on the $1 \%$ national sample survey of 2005 , no effect for female individuals, and early retirement has no effect on health condition of both male and female individuals [12]. Retirement has a negative impact on self-rated health condition based on the data from the CHARLS, and the individuals with low level of education are more likely to be influenced [13].

There are few existing literatures that specifically study the impact of retirement on residency model. This paper examines the influence on the individual's residency model from the angle of retirement.

\section{Empirical Analysis}

\subsection{Data and Variables}

The data used in this paper comes from CHARLS of 2013 and 2015. The main survey individuals of CHARLS are aged over 45 . The survey mainly includes personal basic information, medical services and medical insurance, health status, family structure and financial support, basic community conditions, job, retirement, and pensions. The survey covers 150 districts and counties across China, and then draws 3 village-level units (or communities) from each district and county to a total of 450 villages (or communities). Based on the types of accounts shown in the survey, this paper deleted the agricultural accounts and the accounts which used to be agricultural accounts in the past years. Considering that most of the elderly aged over 75 may have very different characteristics, the sample of the elderly aged over 75 is deleted. At last, the sample is consist of non-agricultural residents aged 45 to 75 .

Whether the individuals share co-residence with their children is the independent variable of this paper, and it is a dummy variable. According to the CHARLS questionnaire, if the respondent has at least one child who lives at home, the individual will be entitled to share co-residence with their children, and the value of the independent variable takes 1 , otherwise, the value takes 0 . Considering that children still attending school do not have significant support for the elderly, the resident information of adult children without attending school in the questionnaire is used to determine the residency model of the elderly.

The core dependent variable retirement is a dummy variable. If the respondent answers "yes" to either of the questions "Whether or not you handled your 
retirement procedures (including early retirement)" and "If you have gone through retirement", it means that the individual has retired, and the value is 1; otherwise it is not retired, and the value is 0 . The results of literature studies have shown that whether the elderly sharing co-residence with their children is also affected by other factors such as age, gender, marital status, education level, number of children alive, and number of deceased children. Therefore, these characteristics will be introduced in the analysis of this paper to control their potential influence. The age statistics are calculated according to the questionnaire provided by the respondent's birth date; set the gender as a dummy variable, the value of the male takes 1 , and the female takes 0 ; the marital status is also set as a dummy variable, the value of those who has a spouse (married or cohabiting) will take 1 , and no spouse (married but separated, divorced, widowed or unmarried) takes 0 . The level of education is measured by the highest degree which the individual has obtained. The higher the level of education, the bigger the value; the number of children alive and the number of deceased children are counted based on the children's information. In addition, other factors which reflect individual's characteristics such as house ownership, assets, health condition, and self-care ability may also affect the residency model. When the house is owned by a family member, the value takes 1 ; otherwise, it is 0 ; assets refers to the cash amount and bank deposit status of the elderly which takes a logarithmic conduction; according to the questionnaire survey results, the better of the health condition is, the bigger of the value is. The better of the self-care ability is, the smaller of the value is. Descriptive statistics are shown in Table 2.

\subsection{Econometric Model}

This paper analyzes the impact of retirement on individual's residency model based on the following equation.

$$
y_{i t}=\beta_{0}+\beta_{1} \cdot \text { Retirement }_{i t}+\alpha \cdot Z_{i t}+\gamma_{\text {year }}+\gamma_{\text {province }}+\varepsilon_{i t}
$$

$y_{i t}$ is the independent variable of this paper. It indicates whether the individuals share co-residence with their children after retirement. When $y_{i t}=1$, it means that they share co-residence with their children. When $y_{i t}=0$, it indicates that they do not share co-residence with their children. Retirement ${ }_{i t}=1$ indicates that they have retired. Retirement ${ }_{i t}=0$ means that there is no retirement, and then the coefficient $\beta_{1}$ represents the impact of retirement on the probability of individual's sharing co-residence with their children. $Z_{i t}$ is a control variable vector used to control the influence of the factors such as age, gender, education, health, and asset status. $\alpha$ is the coefficient vector.

Considering that the sample is panel data, the fixed-effect model is used to control the influence of time and regional factors on the estimation results. $\gamma_{\text {year }}$ represents the annual fixed effects, used to control the impact of the undetected variables that do not change with the individuals but change over time; $\gamma_{\text {province }}$ represents the fixed effects of province to control the possible impact of different 
Table 2. Descriptive statistics.

\begin{tabular}{ccccccccccc}
\hline \multirow{2}{*}{ Variable } & \multicolumn{3}{c}{2013} & & & & & \multicolumn{2}{c}{ Total } \\
\cline { 2 - 9 } & Count & Mean & Variance & Count & Mean & Variance & Count & Mean & Variance \\
\hline Co-residence & 2682 & 0.450 & 0.498 & 3123 & 0.451 & 0.498 & 5805 & 0.451 & 0.498 \\
Retirement & 2642 & 0.435 & 0.496 & 2927 & 0.398 & 0.490 & 5569 & 0.416 & 0.493 \\
Age & 2682 & 65.578 & 4.238 & 3123 & 65.720 & 4.154 & 5805 & 65.654 & 4.193 \\
Gender & 2681 & 0.490 & 0.500 & 3123 & 0.481 & 0.500 & 5804 & 0.485 & 0.500 \\
Education & 2680 & 3.688 & 2.071 & 2977 & 3.697 & 2.062 & 5657 & 3.693 & 2.066 \\
Marriage & 2680 & 0.859 & 0.348 & 3065 & 0.866 & 0.340 & 5745 & 0.863 & 0.344 \\
Assets & 2328 & 6.971 & 3.113 & 2815 & 7.276 & 3.133 & 5143 & 7.138 & 3.127 \\
Health condition & 2661 & 1.987 & 0.694 & 2910 & 1.980 & 0.666 & 5571 & 1.983 & 0.680 \\
Number of children alive & 2682 & 2.792 & 1.309 & 3123 & 2.636 & 1.289 & 5805 & 2.708 & 1.301 \\
Number of deceased children & 2682 & 0.085 & 0.313 & 3123 & 0.133 & 0.458 & 5805 & 0.111 & 0.398 \\
Self-care ability & 2652 & 6.564 & 1.867 & 3032 & 6.568 & 1.714 & 5684 & 6.566 & 1.787 \\
House ownership & 2567 & 0.880 & 0.325 & 2955 & 0.855 & 0.352 & 5522 & 0.866 & 0.340 \\
\hline
\end{tabular}

Source of data: CHARLS of 2013 and 2015.

provinces. $\varepsilon_{i t}$ represents the random error term used to control the effects of other factors not included in the model.

\section{Empirical Results}

The entire sample is examined based on regression Equation (1). The regression results are shown in Table 3. From column (1) in Table 3, it can be seen that without adding any control variables and without controlling the annual fixed effects and the fixed effects of the province, retirement reduces the probability of individual's sharing co-residence with their children by $11.8 \%$, the result is significant at $1 \%$ level of significance; From column (2), it is shown that under the condition of adding the control variables but without controlling the annual fixed effects and the fixed effects of the province, retirement reduces the probability of individual's sharing co-residence with their children by $7.9 \%$, the result is significant at $1 \%$ level of significance; From column (3), it is shown that under the condition of adding control variables and controlling annual fixed effects and fixed effects of the province, retirement reduces the probability of individual's sharing co-residence with their children by $6.9 \%$, the result is significant at $1 \%$ level of significance. It follows that retirement will significantly reduce the probability of individual's sharing co-residence with their children.

Based on the regression Equation (1), male and female samples are separately subjected to regression analysis. The results are shown in Table 4. From column (2) in Table 4, it is shown that under the condition of adding control variables and controlling annual fixed effects and fixed effects of the province, retirement reduces the female individual's probability of sharing co-residence with their 
Table 3. Overall regression.

\begin{tabular}{|c|c|c|c|}
\hline & (1) & (2) & (3) \\
\hline \multirow[t]{2}{*}{ Retirement } & $-0.118^{\star * *}$ & $-0.079^{* * *}$ & $-0.069^{* * *}$ \\
\hline & $(0.01)$ & $(0.02)$ & $(0.02)$ \\
\hline \multirow[t]{2}{*}{ Age } & & $-0.012^{* * *}$ & $-0.012^{\star * *}$ \\
\hline & & $(0.00)$ & $(0.00)$ \\
\hline \multirow[t]{2}{*}{ Gender } & & 0.0190 & 0.0180 \\
\hline & & $(0.01)$ & $(0.01)$ \\
\hline \multirow[t]{2}{*}{ Education } & & -0.0050 & -0.0060 \\
\hline & & $(0.00)$ & $(0.00)$ \\
\hline \multirow[t]{2}{*}{ Marriage } & & $-0.119^{* * *}$ & $-0.102^{\star * *}$ \\
\hline & & $(0.02)$ & $(0.02)$ \\
\hline \multirow[t]{2}{*}{ Assets } & & $-0.010^{* * *}$ & $-0.012^{\star * \star}$ \\
\hline & & $(0.00)$ & $(0.00)$ \\
\hline \multirow[t]{2}{*}{ Health condition } & & $0.036^{* * *}$ & $0.037^{\star * *}$ \\
\hline & & $(0.01)$ & $(0.01)$ \\
\hline \multirow[t]{2}{*}{ Number of children alive } & & $0.011^{*}$ & 0.0090 \\
\hline & & $(0.01)$ & $(0.01)$ \\
\hline \multirow[t]{2}{*}{ Number of deceased children } & & 0.0150 & 0.0140 \\
\hline & & $(0.02)$ & $(0.02)$ \\
\hline \multirow[t]{2}{*}{ Self-care ability } & & 0.0030 & 0.0040 \\
\hline & & $(0.01)$ & $(0.01)$ \\
\hline \multirow[t]{2}{*}{ House ownership } & & $0.134^{\star * *}$ & $0.135^{\star * *}$ \\
\hline & & $(0.02)$ & $(0.02)$ \\
\hline \multirow[t]{2}{*}{ Cons } & $0.504^{* * *}$ & $1.188^{\star * *}$ & $1.185^{\star * *}$ \\
\hline & $(0.01)$ & $(0.13)$ & $(0.13)$ \\
\hline Annual fixed effects & no & no & yes \\
\hline Fixed effects of province & no & no & yes \\
\hline $\mathrm{N}$ & 5569 & 4801 & 4801 \\
\hline $\mathrm{R}^{2}$ & 0.0140 & 0.0420 & 0.0790 \\
\hline
\end{tabular}

Notes: Standard errors in parentheses ${ }^{*} \mathrm{p}<0.1,{ }^{* *} \mathrm{p}<0.05$, ${ }^{* * *} \mathrm{p}<0.01$; Source of data: CHARLS of 2013 and 2015.

children by $6.9 \%$, the result is significant at $1 \%$ level of significance; From column (4), it is shown that under the condition of adding control variables and controlling annual fixed effects and fixed effects of the province, retirement reduces the male individual's probability of sharing co-residence with their children by $7.4 \%$, the result is significant at $1 \%$ level of significance.

At the same time, this paper also finds that marriage, health condition, and self-care ability can significantly affect the female individual's probability of sharing co-residence with their children, but it has no significant effect on male individuals. 
Table 4. The difference caused by gender.

\begin{tabular}{|c|c|c|c|c|}
\hline & \multicolumn{2}{|c|}{ Female } & \multicolumn{2}{|c|}{ Male } \\
\hline & (1) & (2) & (3) & (4) \\
\hline \multirow[t]{2}{*}{ Retirement } & $-0.075^{* * *}$ & $-0.069^{* * *}$ & $-0.089^{* * *}$ & $-0.074^{\star * \star}$ \\
\hline & $(0.03)$ & $(0.03)$ & $(0.02)$ & $(0.03)$ \\
\hline \multirow[t]{2}{*}{ Age } & $-0.016^{* * *}$ & $-0.016^{* * *}$ & $-0.008^{\star * *}$ & $-0.008^{\star * *}$ \\
\hline & $(0.00)$ & $(0.00)$ & $(0.00)$ & $(0.00)$ \\
\hline \multirow[t]{2}{*}{ Gender } & 0.0000 & -0.0060 & $-0.011^{\star}$ & $-0.010^{*}$ \\
\hline & $(0.01)$ & $(0.01)$ & $(0.01)$ & $(0.01)$ \\
\hline \multirow[t]{2}{*}{ Education } & $-0.165^{* * *}$ & $-0.147^{* * *}$ & -0.0050 & 0.0100 \\
\hline & $(0.03)$ & $(0.02)$ & $(0.04)$ & $(0.04)$ \\
\hline \multirow[t]{2}{*}{ Marriage } & $-0.011^{* * *}$ & $-0.011^{* * *}$ & $-0.009^{* * *}$ & $-0.012^{* * *}$ \\
\hline & $(0.00)$ & $(0.00)$ & $(0.00)$ & $(0.00)$ \\
\hline \multirow[t]{2}{*}{ Assets } & $0.052^{\star * *}$ & $0.055^{* * *}$ & 0.0180 & 0.0170 \\
\hline & $(0.02)$ & $(0.02)$ & $(0.02)$ & $(0.02)$ \\
\hline \multirow[t]{2}{*}{ Health condition } & 0.0050 & 0.0020 & $0.019^{* *}$ & $0.017^{\star}$ \\
\hline & $(0.01)$ & $(0.01)$ & $(0.01)$ & $(0.01)$ \\
\hline \multirow[t]{2}{*}{ Number of children alive } & 0.0000 & -0.0020 & 0.0330 & 0.0290 \\
\hline & $(0.02)$ & $(0.02)$ & $(0.03)$ & $(0.03)$ \\
\hline \multirow[t]{2}{*}{ Number of deceased children } & $0.015^{\star *}$ & $0.019^{* * *}$ & -0.0100 & -0.0120 \\
\hline & $(0.01)$ & $(0.01)$ & $(0.01)$ & $(0.01)$ \\
\hline \multirow[t]{2}{*}{ Self-care ability } & $0.140^{\star * \star}$ & $0.148^{\star * *}$ & $0.119^{* * *}$ & $0.113^{* * *}$ \\
\hline & $(0.03)$ & $(0.03)$ & $(0.03)$ & $(0.03)$ \\
\hline \multirow[t]{2}{*}{ House ownership } & $1.401^{\star \star \star}$ & $1.343^{* * *}$ & $0.964^{* * *}$ & $1.017^{\star * *}$ \\
\hline & $(0.18)$ & $(0.18)$ & $(0.19)$ & $(0.19)$ \\
\hline Annual fixed effects & no & yes & no & yes \\
\hline Fixed effects of province & no & yes & no & yes \\
\hline $\mathrm{N}$ & 2471 & 2471 & 2330 & 2330 \\
\hline $\mathrm{R}^{2}$ & 0.0580 & 0.103 & 0.0360 & 0.0690 \\
\hline
\end{tabular}

Notes: Standard errors in parentheses ${ }^{*} \mathrm{p}<0.1,{ }^{* *} \mathrm{p}<0.05,{ }^{* * *} \mathrm{p}<0.01$; Source of data: CHARLS of 2013 and 2015.

\section{Conclusions}

Based on the data from CHARLS of 2013 and 2015, this paper explores the impact of retirement on individual's residency model. The full-sample regression results show that retirement reduces the probability of individual's sharing co-residence with their children by $6.9 \%$; regression analysis of male and female samples indicates that retirement has a greater impact on male individuals.

China has entered an aging society, how to make the elderly have a happy life in their old age has always been a subject of great concern to the society. It is believed that the elderly should be taken good care of by their children and share co-residence with their children. What's more, this is also traditional virtues in 
China. However, the results of this study show that retirement will significantly reduce the probability of individual's sharing co-residence with their children. Faced with this situation, the children should respect the elderly's own life wishes, and take good care of the elderly, so that the elderly can have a happy life in their old age.

\section{References}

[1] Budak, M.-A. and Kawabe, H.L.K.-L. (1996) Co-Residence of Household Heads with Parents in Japan: A Multivariate Explanation. International Journal of Population Geography, 2, 133. https://doi.org/10.1002/(SICI)1099-1220(199606)2:2<133::AID-IJPG16>3.0.CO;2-4

[2] Evans, B. and Palacios, R. (2015) An Examination of Elderly Co-Residence in the Developing World. Social Protection \& Labor Policy \& Technical Notes. World Bank, Washington DC.

[3] Bongaarts, J. and Zimmer, Z. (2002) Living Arrangements of Older Adults in the Developing World: An Analysis of Demographic and Health Survey Household Surveys. Journals of Gerontology, 57, S145. https://doi.org/10.1093/geronb/57.3.S145

[4] Qu, J.Y. and Sun, L.J. (2011) The Arrangement and Change of Old People in China: 2000-2006. Journal of Population Sciences, No. 2, 40-45.

[5] Shah, N.M., Badr, H.E. and Yount, K. (2011) Decline in Co-Residence of Parents and Children among Older Kuwaiti Men and Women: What Are the Significant Correlates? Journal of Cross-Cultural Gerontology, 26, 157. https://doi.org/10.1007/s10823-011-9138-x

[6] Lin, M.X., Jin, Y.J. and Liu, Y.C. (2009) A Comparative Study on the Choice of Habits for Older People in China and Korea. Journal of Northwest Normal University (Social Science), 46, 71-79.

[7] Yang, E.Y., Qi, J.S. and Ma, G.R. (2012) An Empirical Analysis of the Influencing Factors of Residential Arrangement for the Elderly in Rural China. Agricultural Economic Issues, No. 1, 37-44.

[8] Isengard, B. and Szydlik, M. (2012) Living Apart (or) Together? Coresidence of Elderly Parents and Their Adult Children in Europe. Research on Aging, 34, 449-474. https://doi.org/10.1177/0164027511428455

[9] Qu, J.Y. and Du, P. (2014) The Influence of Residents' Willingness of Living in Urban China on Empty Nest Residence. Population and Development, 20, 87-94.

[10] Zhang, K.Z. and Jiang, Q.C. (2013) Ageing, Retirement, and Consumption: Does China Exist "The Retirement-Consumption Riddle"? Population and Economy, No. $5,10-18$

[11] Wang, Q. and Zeng, G. (2015) The Influence of Retirement and Pension Income on Subjective Well-Being-An Empirical Research Based on CHARLS. Insurance Studies, No. 11, 95-109.

[12] Lei, X., Strauss, J. and Tian, M. (2015) Living Arrangements of the Elderly in China: Evidence from the CHARLS National Baseline. China Economic Journal, 8, 191. https://doi.org/10.1080/17538963.2015.1102473

[13] Dong, X. and Zang, W. (2017) The Effect of Retirement on the Health of Middle-Aged and Elderly People. Population Journal, No. 1, 76-88. 